\title{
Good government for small countries
}

The tendency for the world to be sprinkled with small countries has recently accelerated, and is disconcerting, but may yet offer a solution for British Ulster, where 26 people have been killed since the year began.

ARE we heading for a world of microstates? One perplexing accompaniment of the break-up of the Soviet empire is the emergence of would-be nation states with populations of five million or so, an order of magnitude less than those of even middle-sized powers such as Britain and France. Apart from the three Baltic states, there are at least Romanian Moldavia, Slovenia and Croatia (the pieces into which Yugoslavia has already broken); Slovakia hankers after separation from Czechoslovakia and $\mathrm{Mr}$ Boris Yeltsin has yet to come to grips with the centrifugal tendencies of the autonomous regions with which vast Russia is dotted (but he must know that something will have to be done about North Ossettia, in the Caucasus, which wants separation from Russia, but not union with Georgia to the south).

Fissiparous tendencies are more widespread. Belgium is already two separate states (see Nature 355, 579; 1991). Now, according to the pre-election British opinion polls, there is a resurgence of Scottish opinion in favour of separation from the United Kingdom (which opinion the opposition Labour party would mollify with an elected Scottish parliament). Unconvincingly, Welsh nationalists have taken up the cry. Where will it all end?

In further decentralization; there is no doubt of that. Events in the former Soviet Union have strengthened hankerings after democratic procedures and self-determination everywhere, while economic groupings such as the European Communities have made the option more credible: given a free market in goods and services, quite small parts of Europe may prefer to opt for formal self-determination in regional matters.

So why is the tendency towards microstatehood perplexing? It is not just that there are now more names to remember, and a greater variety of national aspirations for diplomats to take account of. More seriously, microstates can rarely be economically self-contained (unless they are strictly agrarian, as enlightened as Costa Rica or, otherwise, as technically sophisticated as Switzerland). Yet with the civil war in Nicaragua ended, even the handful of microstates in Central America might be drawn into a productive economic union (which the United States is best placed to foster).

The more substantial hazards are not economic. Usually, microstates can defend themselves only by alliances with others or with more powerful patrons - the recipe for the perfidious horse-trading that made eighteenth- century Europe a nightmare. Worse still, because many of the emerging microstates are founded on an ethnic or cultural identity, their existence assaults the liberal doctrine that modern civility requires that people who think of themselves differently should nevertheless be able to live together productively.

The immediate danger is that newly independent microstates founded on supposed national aspirations will oppress the minorities they embody. What exactly are the arrangements in the Baltic states to safeguard the rights of their substantial Russian minorities, or in Croatia (as defined by the ceasefire line) for the protection of the Serbs who live there? What protection is there, throughout Central Europe, from anti-Semitism? Recent welcomes for emergent microstates as proofs that illiberal governments have fallen should have been more widely tempered by insistence that seemly rules should be in place and that they will be followed. Otherwise, the immediate risk of unjust oppression will be followed by that of conflict on behalf of the oppressed (or supposedly oppressed) - Europe's 1930s nightmare. Luckily, there is now a framework within which such complaints can be raised: the Conference on Security and Cooperation in Europe (CSCE). It must be used more vigorously.

But there are, sadly, several microstates in which this remedy will not serve. One of them is British Ulster, where 26 people had been killed in the first six weeks of this year. (Others are Nagorno-Karabakh, the Armenian enclave in Azerbaijan, Indonesia's East Timor and Kashmir.) Ulster is not, of course, an independent state, but a part of the United Kingdom. The electoral majority, mostly Protestant by religious persuasion, want things to stay like that. Some others, variously described as nationalists or republicans, would prefer anschluss with the Republic of Ireland (whose constitution declares the aim of islandwide authority, but which also gives the Roman Catholic Church a special place).

Despite an agreement on consultation between London and Dublin (over the objections of the Protestant Unionists), things go from bad to worse; more people are killed, and business life is increasingly corrupted by protection rackets. Now that microstates are back in fashion, should not Ulster (with nearly two million people) join their ranks, but on the understanding that the British and Irish governments would share responsibility for keeping the peace so long as that is necessary, the next half-century or so? 